\title{
Robust Vehicle Suspension System by Converting Active \& Passive Control of a Vehicle to Semi-Active Control System Analytically
}

\author{
Hassan Elahi, Asif Israr, M. Zubair Khan, and Shamraiz Ahmad \\ Department of Mechanical Engineering, Institute of Space Technology, Islamabad, Pakistan \\ Email: \{hassan.elahi, asif.israr, m.zubair, shamraiz.ahmad\}@ @ist.edu.pk
}

\begin{abstract}
This research article deals with a simplified translational model of an automotive suspension system which is constructed by considering the translation motion of one wheel of a car. Passive Vehicle Suspension System is converted into Semi Active Vehicle System. Major advantage achieved by this system is that it adjusts the damping of the suspension system without the application of any actuator by using MATLAB $®$ simulations. The semiactive control is found to control the vibration of suspension system very well.
\end{abstract}

Index Terms - vibration control, translational model, vehicle suspension system, active control system, passive control system

\section{INTRODUCTION}

Suspension system separates the wheel of the vehicle form the vehicle body in order to avoid any jerks due to rough roads. They ensure the comfort of the passengers by absorbing shocks and dissipating them. A conventional vehicle Suspension System constitutes of a damper (energy dissipating element) and a helical or leaf spring (energy storing element) [1]. Since no energy can be added by these two elements, such suspension system is called passive vehicle suspension system.

There are limitations of passive vehicle suspension system due to a compromise between spring rate and damping characteristics in order to achieve required output [2]. A single degree of freedom spring mass damper with high damping value can perform well in the vicinity of high frequency [3], [4]. Due to this compromise between spring rate and damping, active and semi-active systems are gaining reputations in the suspension systems. Passive and active suspension systems are shown in Fig. 1.

Semi Active System utilizes external source of power for the sake of adjusting damping levels, for operating embedded controller and sensors attached. Controller detects the level of damping required by sending signal and automatically adjusting the damping level in a real time. In an automotive suspension this is achieved by the use of an active damper that is attached in parallel to the conventional spring.

In this research paper vehicle suspension model with semi active control system is established in MATLAB and finally their performance are compared on the basis of the result for the MATLAB.

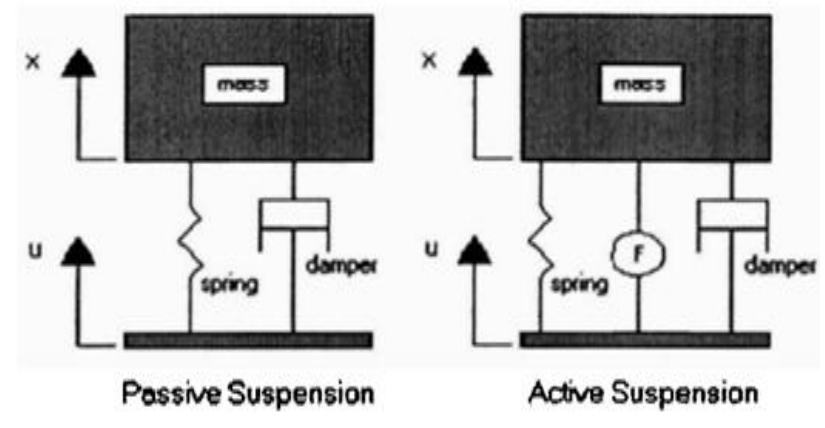

Figure 1. Schematic diagram for passive and active system.

\section{MODELLING AND DESIGN OF SUSPENSION SYSTEM}

A. Physical Model of Passive Vehicle Suspension System

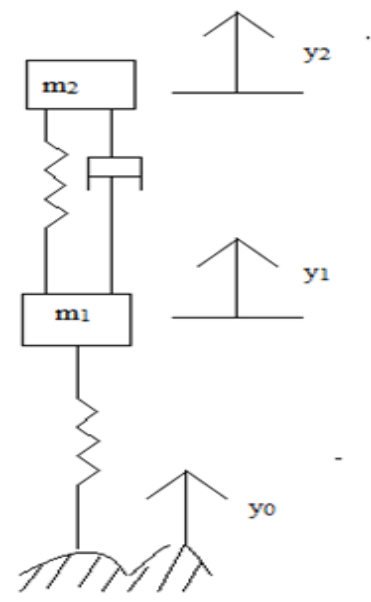

Figure 2. Free body diagram for quarter suspension system 
A quarter vehicle suspension systems [5] are shown in Fig. 2. This model is used to check the performance of the other semi active systems. Linear spring is used to model the stiffness of the tire, axle, tire and other moving parts are represented by mass $m_{1}$, suspension system by a spring, viscous damper and supported vehicle components by mass $\mathrm{m}_{2}$ [6].

In the model;

$\mathrm{K}_{1}=$ spring constant showing stiffness of the tire

$\mathrm{m}_{1}=$ mass of the car

$\mathrm{K}_{2}=$ spring constant of the suspension spring

$\mathrm{m}_{2}=$ mass of the wheel of car

Transfer function for open loop system $\mathrm{T}(\mathrm{s})$ can be determined as:

$$
\mathrm{T}(\mathrm{s})=\frac{4 \mathrm{~s}^{2}+3.333 \mathrm{~s}+3.333}{\mathrm{~s}^{4}+5.833 \mathrm{~s}^{3}+9.833 \mathrm{~s}^{2}+3.333 \mathrm{~s}+3.333}
$$

This system shows a steady state error. So the transfer function for closed loop system is:

$$
T(s)=\frac{4 s^{2}+3.333 s+3.333}{s^{4}+5.833 s^{3}+13.83 s^{2}+6.667 s+6.667}
$$

All the closed loop poles lie in left half of root locus diagram as shown in Fig. 3 so the system is stable. But response time is very high (less than a second is the requirement) as depicted in figure with blue curve.

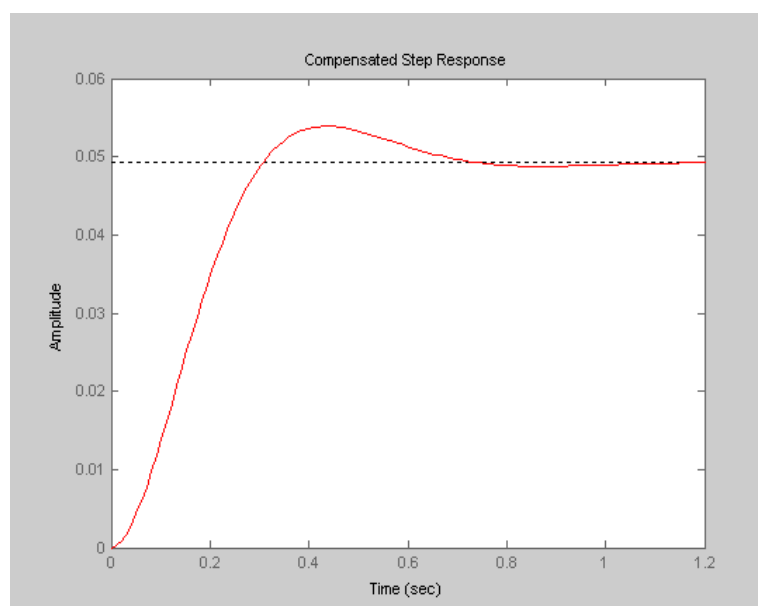

Figure 3. Time response for observer design.

\section{B. Controller Design}

It is evident from the above discussion that assuming system depicted in Fig. 3 is stable and can be controlled by using either semi active or active system. Most common semi active control policy is Skyhook control. For this controller, introduce extra pole in a system so that the location of all closed loop poles can be controlled [7], [8]. This control system should be designed to have a maximum overshoot of $10 \%$ (but we designed it for $9.5 \%$ to avoid any non-linearity) and a settling time of $.8 \mathrm{sec}$ (design for .74sec) [9].

After solving by state space variable method the transfer function is:

$$
T(s)=\frac{1.421 e-014 s^{3}+4 s^{2}+3.333 s+3.333}{s^{4}+11.64 s^{3}+91.11 s^{2}+76.72 s+67.71}
$$

Solving the above transfer function with MATLAB the time response diagram of the control system is shown in Fig. 4. It reveals a large steady state error but required time response. So system is controllable. Steady state error can be reduced via integral control but we switch to other systems to avoid complexity.

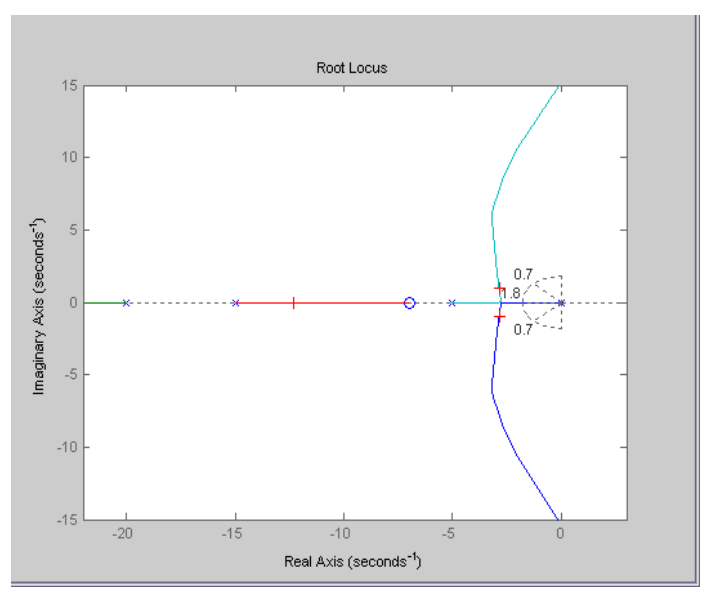

Figure 4. Loop poles and root loci.

\section{Controller Design}

To avoid cost and equipment observer design is preferred over controller design. Moreover it may as faster as 10 times than that of the controller [10, 11], so we find the results by designing an observer for the suspension system.

Solving the above with required inputs, transfer function is obtained as below:

$$
G(s)=\frac{-2.842 e-014 s^{3}+4 s^{2}+3.333 s+3.333}{s^{4}+108.9 s^{3}+8217 s^{2}+6861 s+6771}
$$

By solving the above transfer function for the observer design we have time response diagram for the observer. It is clear from the Fig. 5 that time response for the observer is nearly ten times higher than the previous one but steady state error is too higher which shows that system is highly unstable.

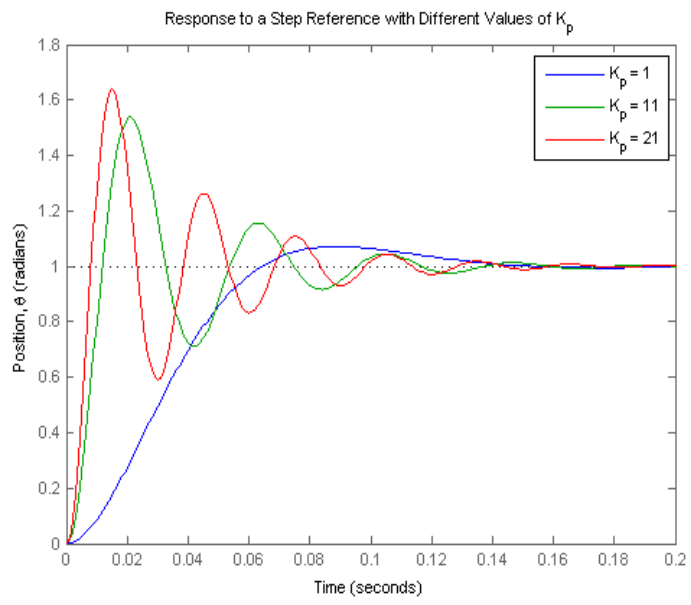

Figure 5. Time response diagram for a controller. 


\section{SYSTEM ANALYSIS AND DICUSSION}

\section{A. Nyquist Criterion}

The contribution due to Nyquist is of very mathematical nature and deals also with the system which is unstable in open loop.

System whose open-loop frequency response loci do not encircle the -1 point will be stable in closed loop, i.e. their open loop gain is less than unity at the phasecrossover frequency [12]. Loci of the system which encircle the -1 point are unstable in closed loop. Loci of the system which pass through the -1 point are marginally stable and will oscillate continuously at the phase-cross frequency [13]. The time response diagram of the control system is shown in Fig. 6 using MATLAB.

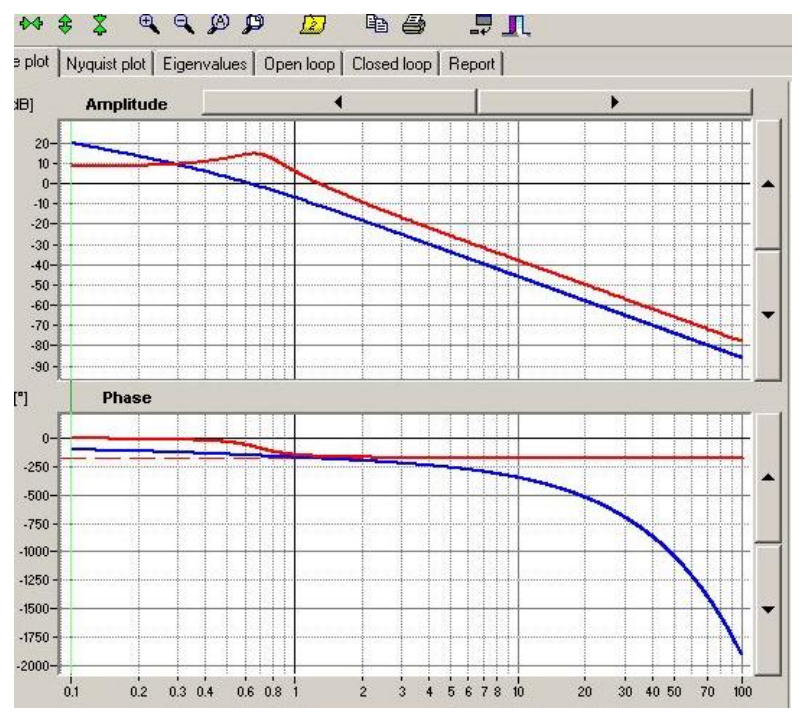

Figure 6. Stability via nquist.

It reveals a large over shoot, settling time and oscillations. So system is unstable. In the compensated response the system has large steady state error and settling time. The Nyquist diagram is shown in Fig. 7.

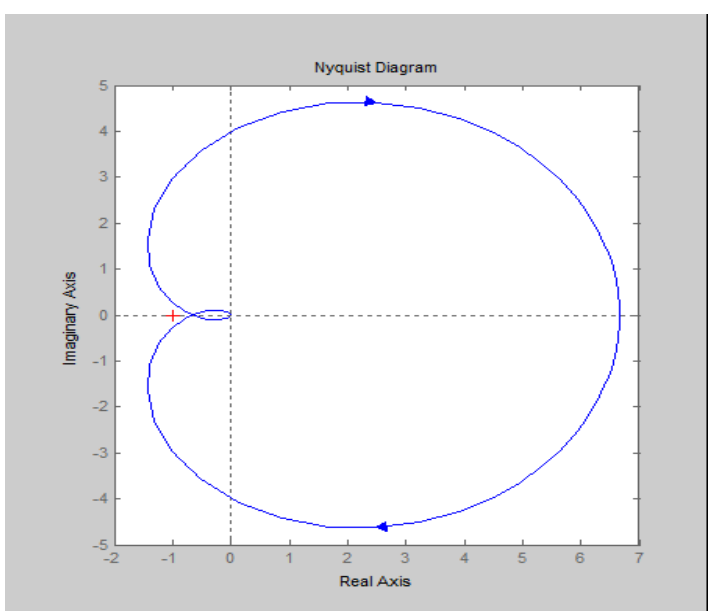

Figure 7. Nyquist dagram.

\section{B. Bode Plot}

In bode plot the logarithm of the magnitude of transfer function is plotted against the logarithmic frequency function $\omega$. The phase $\varphi$ of the transfer function is plotted separately against the logarithmic frequency [14].

The transfer function is given by following equation:

$$
G=\frac{4 s^{2}+3.333 s+3.333}{s^{4}+5.833 s^{3}+9.833 s^{2}+3.333 s+3.33}
$$

The logarithmic gain in $\mathrm{dB}$ vs. $\omega$ is drawn on one set of axis while the phase $\varphi$ vs. $\omega$ is drawn on another set of axis. The Bode plot is shown in the Fig. 8.

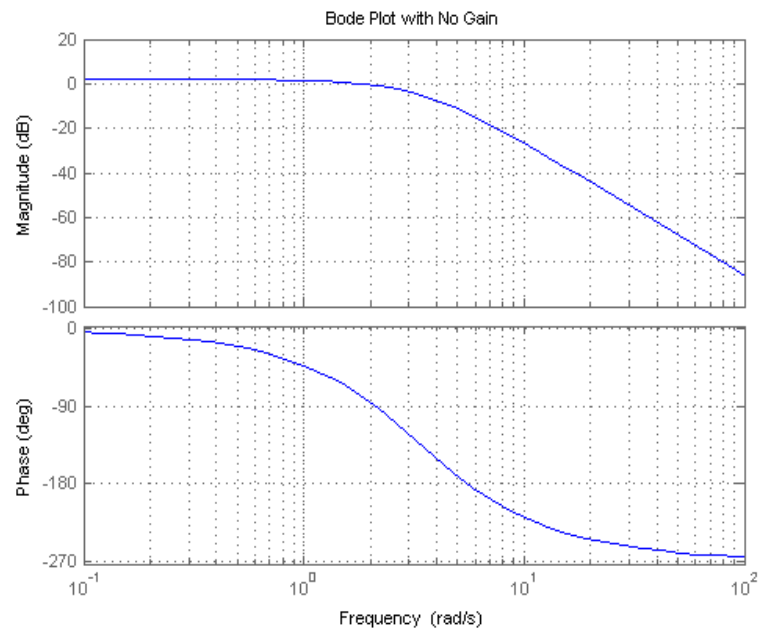

Figure 8. Stability via bode plot

\section{Lag Compensator}

The purpose of a lag compensator is to improve the static error constant by increasing only the low frequency gain without any resulting instability and increase the phase margin of the system to yield the desired transient response [15]. Fig. 9 shows the time response of the lag compensated system using MATLAB. It reveals that the system has over shoot greater than $10 \%$ and settling time up to 10 second. So system is reasonably stable [16].

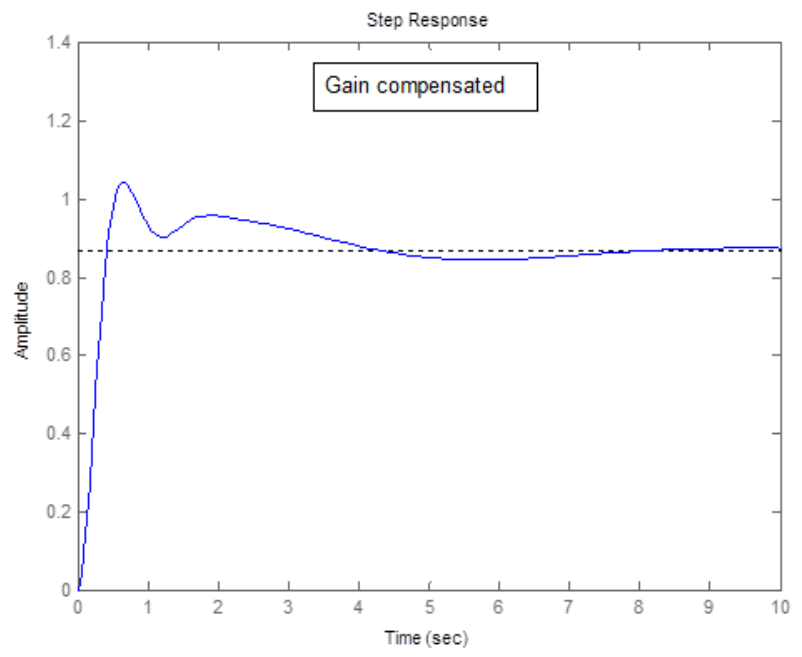

Figure 9. Lag cmpensator.

\section{Lead Compensator}

The purpose of a lead compensator is to increase the bandwidth with the increase in gain crossover frequency. 
While the phase diagram is raised to higher frequencies that results in large phase margin and higher phase margin frequencies [17]. Lower percentage of overshoots with small peak times are obtained in the time domain. Fig. 10 shows the time response of a lead compensated system using MATLAB. It shows that the system has very less over shoot (up to $5 \%$ ) and settling time less than 0.5 second. So system is highly stable.

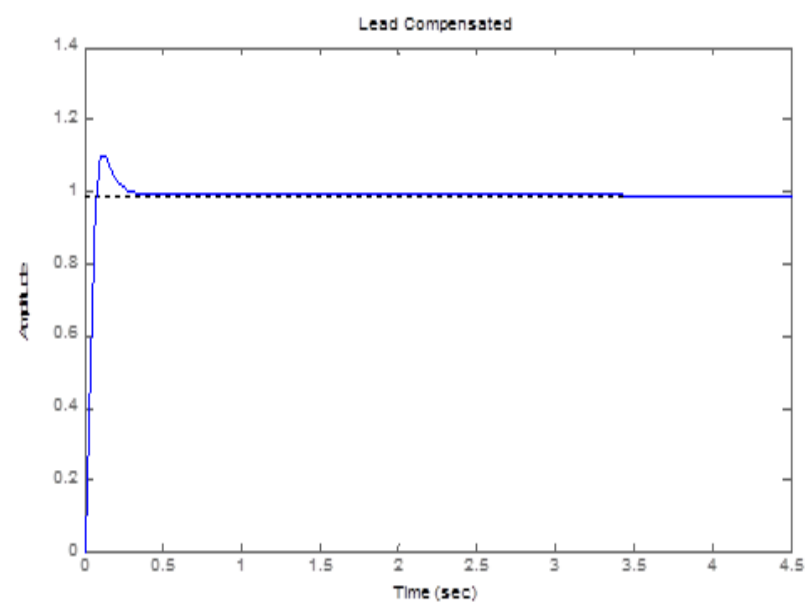

Figure 10. Lead compensator.

\section{E. Lag-Lead Compensator}

The designing technique of Lead and Lag compensation forms the basis for the designing of a laglead compensator using frequency response technique [18].

The frequency response curve is altered by the phase lead portion of the lag-lead compensator by the addition of phase lead angle and an increase in phase margin at the given crossover frequency. Attenuation is provided by the phase lag portion near and above the gain crossover frequency. The time response diagram of the lead compensated system is shown in Fig. 10 using MATLAB. It shows that the system has very less over shoot (up to $5 \%$ ) and settling time less than 0.5 second. So system is highly stable.

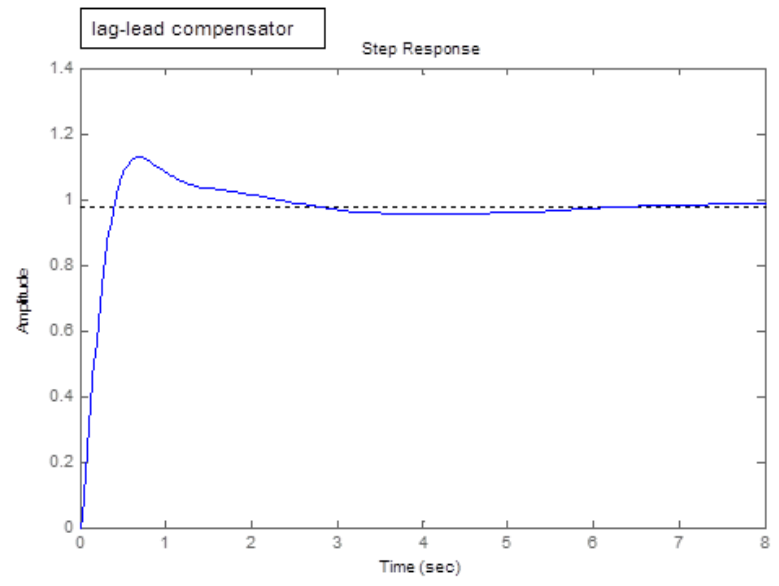

Figure 11. Lag-lead compensator.

\section{CONCLUSIONS}

Following conclusions can be drawn from the current research work:

a. The system is stable under lag, lead and lag-lead compensator.

b. The best suited compensated design is lead compensation under which the system is exceptionally stable.

c. It showed that the system has very less over shoot (up to $5 \%$ ) and settling time less than 0.5 second.

\section{ACKNOWLEDGMENT}

I would like to prompt my sincere gratitude to all those who provided me the possibility to complete this research. A special appreciation I give to Mr. Zeeshan Anjum, Mr. Ashiq and Mr. Arslan, whose influence in stimulating suggestions helped me to coordinate my research especially in writing this paper.

\section{REFERENCES}

[1] G. Yao, et al. "MR damper and its application for semi-active control of vehicle suspension system," Mechatronics, vol. 12, no. 7, pp. 963-973, 2002.

[2] R. Wang, et al. "An investigation on energy recovery analysis of active suspension system," in Proc. 19th International Conference on Automation and Computing, 2013.

[3] D. V. Casteren, et al., "Non-linear full-car modeling and sky-hook control for a direct-drive active suspension system," SAE International Journal of Passenger Cars-Mechanical Systems, vol. 6, no.1, pp. 252-268, 2013.

[4] H. Li, et al., "Adaptive sliding-mode control for nonlinear active suspension vehicle systems using T-S fuzzy approach," IEEE Transactions on Industrial Electronics, vol. 60, no. 8, pp. 33283338, 2013.

[5] K. A. Hair, Passive Vehicle Suspension System, Google Patents, 1994.

[6] A. M. Beard and A. H. V. Flotow, Active Vehicle Suspension System, Google Patents, 1997.

[7] D. Hanafi, "PID controller design for semi-active car suspension based on model from intelligent system identification," in Proc. Second International Conference on Computer Engineering and Applications, 2010.

[8] W. Sun, Z. Zhao, and H. Gao, "Saturated adaptive robust control for active suspension systems," IEEE Transactions on Industrial Electronics, vol. 60, no. 9, pp. 3889-3896, 2013.

[9] F. Beltran-Carbajal, et al., "Control of nonlinear active vehicle suspension systems using disturbance observers," Vibration Analysis and Control-New Trend and Developments, 2011.

[10] V. S. Deshpande, et al., "Disturbance observer based sliding mode control of active suspension systems," Journal of Sound and Vibration, vol. 333, no. 11, pp. 2281-2296, 2014.

[11] O. Katsuhiko, Modern Control Engineering, Pearson Education, 2004.

[12] G. Koch and T. Kloiber, "Driving state adaptive control of an active vehicle suspension system," IEEE Transactions on Control Systems Technology, vol. 22, no. 1, 2014.

[13] B. Zhu, Y. Chen, and J. Zhao, "Integrated chassis control of active front steering and yaw stability control based on improved inverse Nyquist array method," The Scientific World Journal, 2014.

[14] C. D. Richard and H. B. Robert, Modern Control System, Dorling Kindersley Limited, 1998

[15] V. Ozbulur, "An adaptive compensator for a vehicle suspension system," Journal of Vibration and Control, p. 1077546314520831 , 2014.

[16] G. Jack and V. Andy, Control System Design and Simulation, McGRAW-Hill Book Company, 1992.

[17] S. N. Norman, Control Systems Engineering, New York: John Wiley \& Sons, 2003. 
[18] N. Birla and A. Swarup, "Optimal preview control: A review," Optimal Control Applications and Methods, 2014.

[19] J. Lei, et al., "Active vibration control for nonlinear vehicle suspension with actuator delay via I/O feedback linearization," International Journal of Control, p. 1-16, 2014.

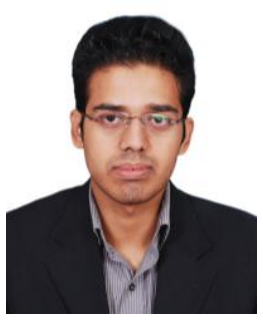

Hassan Elahi has done his Masters of Science by research in Applied Mechanics and Design with Award of Honors from University of Engineering \& Technology, Taxila, Pakistan in 2014. His bachelor degree is in Mechatronics Engineering. He is now teaching mechanical engineering courses to degree classes. During his master's degree he worked on Mechanical Quality Factor of Piezoelectric Material. His research interest includes MEMs, Applied Mechanics and Design, Control Engineering and ElectroMechanics.

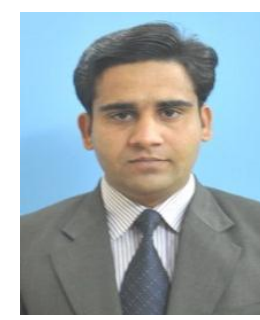

Shamraiz Ahmad has done his Masters of Science by research in Design and Manufacturing Engineering from National University of Sciences and Technology (NUST) Islamabad, Pakistan in 2014. His bachelor degree is in Industrial Engineering and Management from University of Punjab Lahore, Pakistan. He has two years of industrial experience and now teaching mechanifcal and manufacturing engineering courses to degree and diploma classes. During his masters" degree he worked on Design Optimization of Ceiling Fan Blades using Design of Experiments and Response Surface Methodology and experimentally improved the performance of Ceiling Fan. His research interest includes Product Design Optimization, Manufacturing System Improvement \& Optimization, Ergonomics and Quality Engineering. 